\begin{tabular}{ccc}
\hline & International Journal of Engineering \& Technology, $7(1.5)(2018) 90-96$ \\
SPC & International Journal of Engineering \& Technology \\
\hline
\end{tabular}

\title{
Metamaterial inspire multiband monopole antenna with defected ground structure
}

\author{
B T P Madhav*, K Thirumalarao, M Venkateswara Rao, V N V Saiteja, J Kranthi Kumar, P N V S Reavanth \\ Department of ECE, Koneru Lakshmaiah Education Foundation, Andhra Pradesh, India-522502 \\ *Corresponding author E-mail: btpmadhav@kluniversity.in
}

\begin{abstract}
This article represents the design and analysis of a compact antenna of size $34 \mathrm{mmX} 18 \mathrm{mmX} 1.6 \mathrm{~mm}$ on FR-4 substrate material. The designed antenna is having a slot at the partial ground for all iterations are observed and it is analysed with the help of ANSYS 17 Electronics Desktop. A new unit cell design which exhibits the metamaterial property is also analyzed with the help of unit cell analysis. The negative permittivity value is extracted, and that unit cell is implemented in the proposed antenna. The enhanced results have been carried out with comparing iteration wise. The proposed antenna has radiation efficiency of 94\%, it works in the range of for LTE (33-37) band at 1.95-2.04 GHz, WiMAX band 2.87-3.76 GHz and LTE (43-44) bands 5.92-7.2 GHz.
\end{abstract}

Keywords: Band Notch Antenna, Defected Ground (DGS), WiMAX, Unit cell.

\section{Introduction}

Now a day's metamaterials engineered to show various properties which does not exhibit in nature. their varying structures plays a vital role in the electromagnetic environment. Silva et.al proposed an antenna where resonating arrays of microstrip patch antenna loaded with the splitting resonator. the change in the electromagnetic behaviour due to split ring resonator have been observed in the [1]. A pair of splitting resonators loaded on the sides of the feed has been observed in [2] later another pair of the antenna added, and a multiband behaviour of the antenna is observed. Raghavan et.al [3] proposed an antenna which is loaded with split ring resonator for WLAN and WiMAX applications. A measurement of dielectric constant is carried out by Jackson in [4]. Kumar et.al proposed a dual band antenna which of a circular split ring resonator type of a patch covering the bands if WIFI and WiMAX and Bluetooth applications in [5]. In [6] jawed et.al proposed a notch UWB antenna with the help of split ring resonator which are placed on the backside of the antenna. With the multiple split ring resonator on the backside it gives multiple resonance. A reconfigurable loaded split ring resonator $\mathrm{CPW}$ antenna have been seen in [7]. A compact multiple notch band antenna which are loaded with the stepped impedance resonators and split ring resonators are observed in [8] Zheng proposed antenna works in the multiband areas. Planar monopole antenna which covers the bands of WiMAX and Bluetooth have been observed in the [9] proposed antenna. In [10] Yadav et.al proposed antenna which is having a triple notch bands in the ultra-wideband range. The proposed antenna is analysed according to the $\mathrm{S}$ shaped slot in the feed and CSRR on the patch and mirror split ring resonators at the either ends of the feed. Due to this a triple notch band is occurred at the circular patch antenna.it is observed that measured and simulated results are correlated with each other. In Yang [11] proposed a filtenna with the help of split ring resonator and complimentary split ring resonator. He clearly differentiates the difference in the split and complementary split ring resonators for this proposed model the lower cut off frequency is said to be at 3. 7GHz.A band notched ultra-wide band printed monopole antenna have been designed and analysed through the HFSS is observed in [12]. Madhav et al proposed multiple antenna models with defected ground and metamaterial concept [13-21].

In this article a compact antenna is designed with unit cell which is placed on the proposed model to enhances the performance of the antenna. The proposed antenna works at the bands LTE 33-37, WIMAX, LTE 43-47. The proposed antenna designed and analysed using commercially equipped tool ANSYS electronic desktop 17. Results of the proposed antenna with iterations have been exhibited. The result analysis of the antenna has been discussed in subsequent sections

\section{Antenna design}

\subsection{Unit cell analysis}

The approach for design of split ring resonator have been introduced in the below design. The splits in the ring produces wavelength much larger than the normal rectangle. The second split ring resonator which is oriented towards the first rectangular resonator produces the large capacitance. It is because of the gap between the rectangular split ring resonators.

The unit cell analysis is carried by applying the perfect electric conductor on the split side and magnetic conductor as towards the top side of the box. A wave guide port is assigned to remaining ends of the unit cell. The following equation number 3 states the relation between effective dielectric constant and resonant frequency where Leff effective length of the microstrip line. FSRR is the resonant frequency of the split ring resonator and LSRR is the total inductance of the ring as shown in Equation 1. The formula 
for capacitance of split ring resonator is also explained. Through this analysis fig: 2 clearly shows the negative permittivity has been obtained.

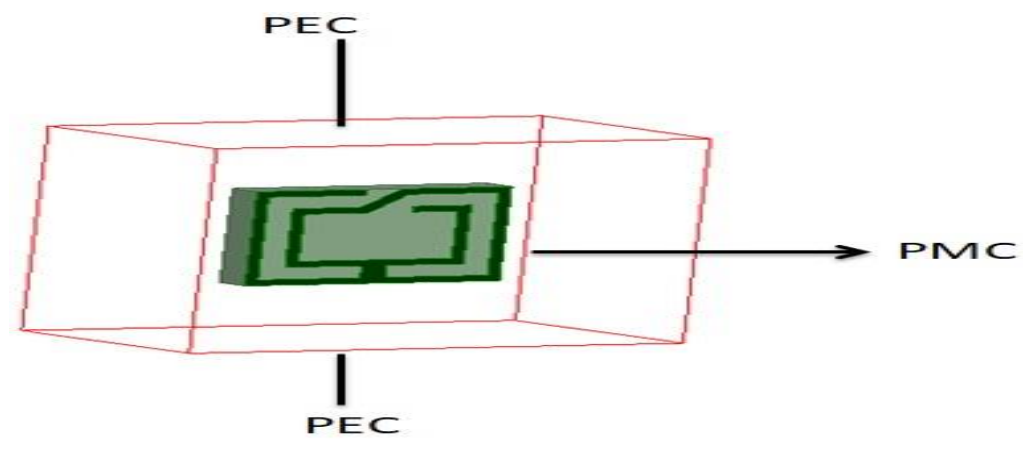

Fig. 1: unit cell analysis view

$$
\begin{aligned}
F_{S R R} & =\frac{1}{\pi \sqrt{L_{S R R} \times C_{S R R}}} \\
C_{S R R} & =P \times C_{P U L} \\
f_{R} & =\frac{C}{\sqrt{\epsilon_{e f f}}} \frac{1}{\sqrt{L_{e f f}}}
\end{aligned}
$$

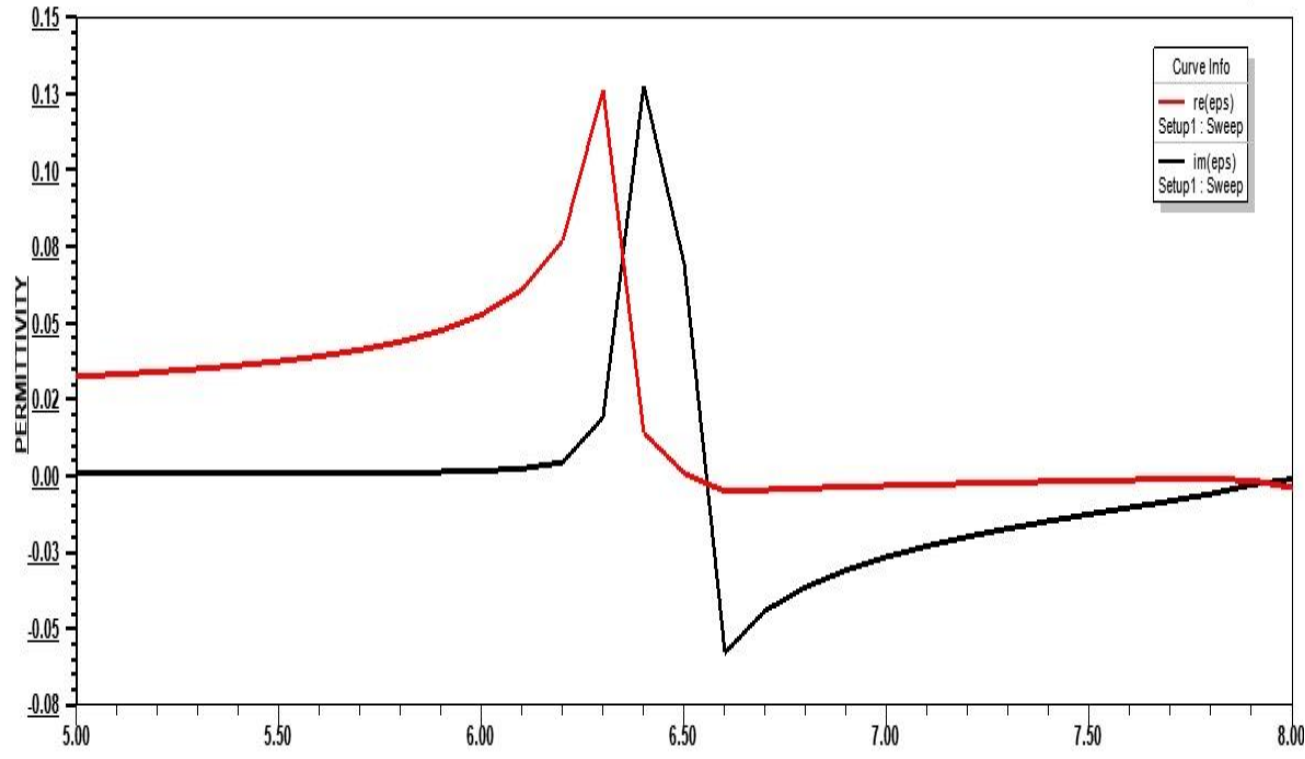

Fig. 2: permittivity vs frequency of the unit cell

\subsection{Antenna design and analysis}

A Compact antenna is designed of length $34 \mathrm{~mm}$ and width $18 \mathrm{~mm}$ on FR4 material having dielectric constant of 4.4 with thickness of $1.6 \mathrm{~mm}$ is analysed using ANSYS ELECTRONIC DESKTOP 17. The partial ground of an antenna is cut with a slot which gives the notch characteristics. A microstrip feed of 50-ohm characteristic impedances is connected through a SMA connector. Proposed model has been extracted from 3 iterations. Model 1 explains a simple design. Model 2 consists of a split ring resonator which is connected to the split ring resonator A new approach of metamaterial split ring design is taken on the opposite side of the feed to extract the metamaterial properties. This approach gives good measurements than other two iterations. The proposed antenna dimensions and measurement table with iterations have seen in the below diagram Fig 3. shows the iterations of the antenna and Fig 4. shows the proposed antenna with parameters the dimensions of the proposed antenna has been shown in table 1 


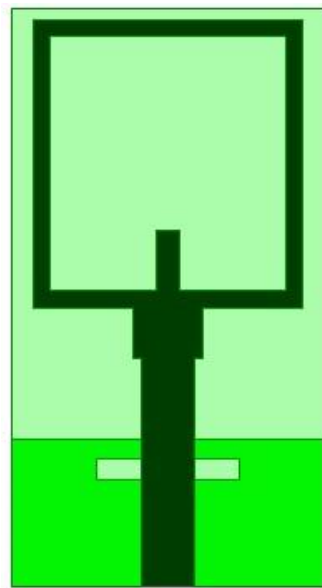

(a)

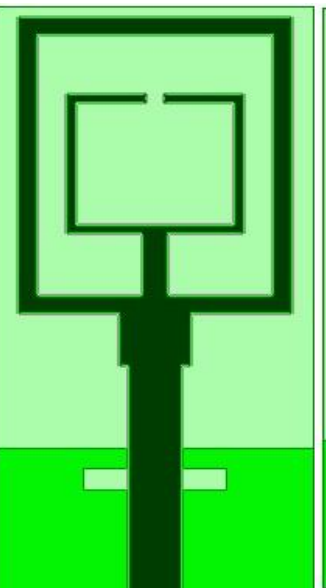

(b)

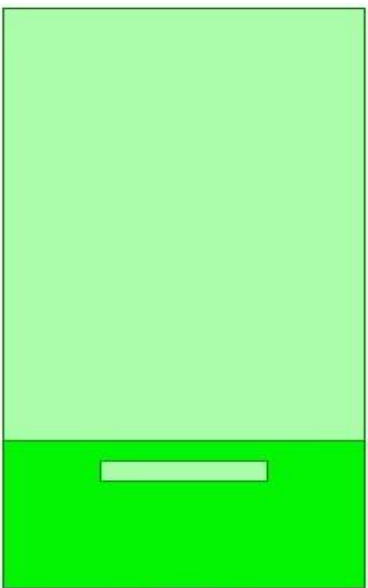

(c)

Fig. 3: (a) and (b) model 1 and model 2 front view (c) common flip view of all models

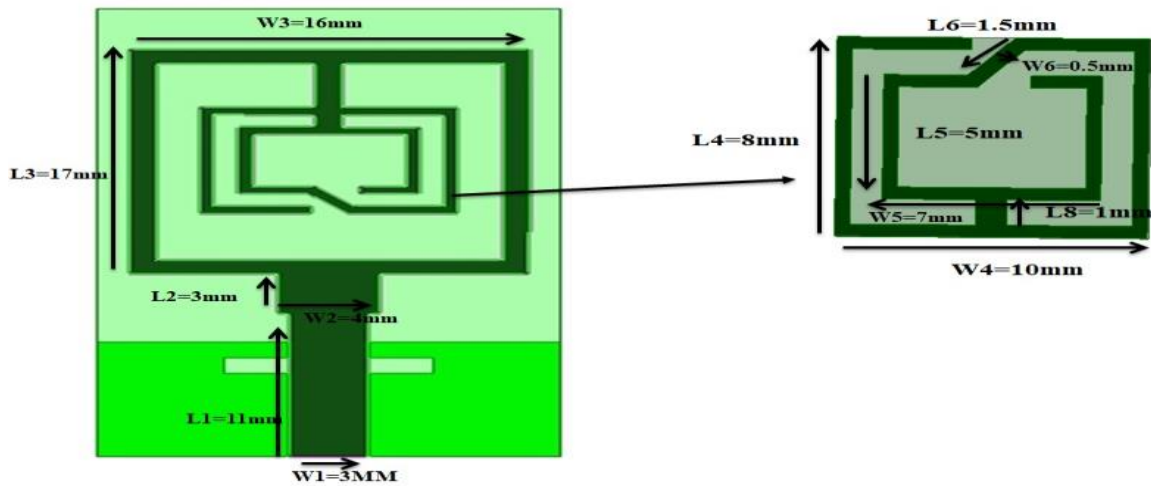

Fig. 4: Proposed Antenna

Table 1: Dimensions of the proposed antenna

\begin{tabular}{|l|l|l|l|}
\hline Ls & $34 \mathrm{~mm}$ & W6 & $0.5 \mathrm{~mm}$ \\
\hline Ws & $18 \mathrm{~mm}$ & L7 & $3.4 \mathrm{~mm}$ \\
\hline L1 & $11 \mathrm{~mm}$ & W7 & $1 \mathrm{~mm}$ \\
\hline W1 & $3 \mathrm{~mm}$ & w5 & $7 \mathrm{~mm}$ \\
\hline L2 & $3 \mathrm{~mm}$ & H & $1.6 \mathrm{~mm}$ \\
\hline W2 & $4 \mathrm{~mm}$ & a & $1 \mathrm{~mm}$ \\
\hline 13 & $17 \mathrm{~mm}$ & G1 & $1.75 \mathrm{~mm}$ \\
\hline W3 & $16 \mathrm{~mm}$ & Lg & $8.5 \mathrm{~mm}$ \\
\hline L4 & $8 \mathrm{~mm}$ & Wg & $18 \mathrm{~mm}$ \\
\hline W4 & $10 \mathrm{~mm}$ & Ws1 & $8.2 \mathrm{~mm}$ \\
\hline L5 & $5 \mathrm{~mm}$ & Ls1 & $1.2 \mathrm{~mm}$ \\
\hline L6 & $1.5 \mathrm{~mm}$ & L8 & $1 \mathrm{~mm}$ \\
\hline
\end{tabular}




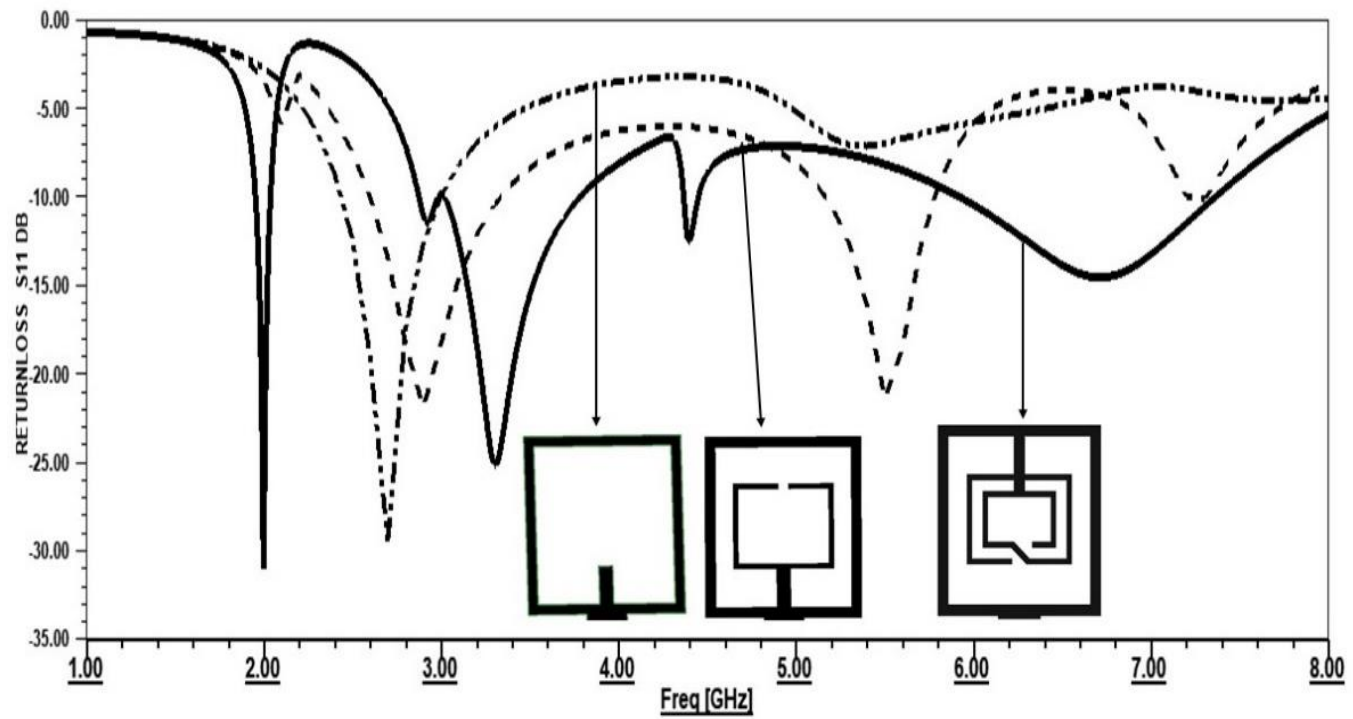

Fig. 5: Return loss of all antennas

Fig 3 shows the return loss characteristics of the three antennas. Model 1 shows the return loss at 2.44 to $3 \mathrm{GHz}$ with a maximum return loss of $-30 \mathrm{db}$. Where as the model 2 shows the dual band characteristics at 2.6 to $3.3 \mathrm{GHz}$ and 5.1 to $5.8 \mathrm{GHz}$ with maximum return loss of $-25 \mathrm{db}$.A new metamaterial design approach has been taken for the proposed model it shows the graph varied at the multiple bands with considerable return loss having a maximum at $2 \mathrm{GHz}$ of $30 \mathrm{db}$.proposed antenna works in LTE bands and WiMAX.

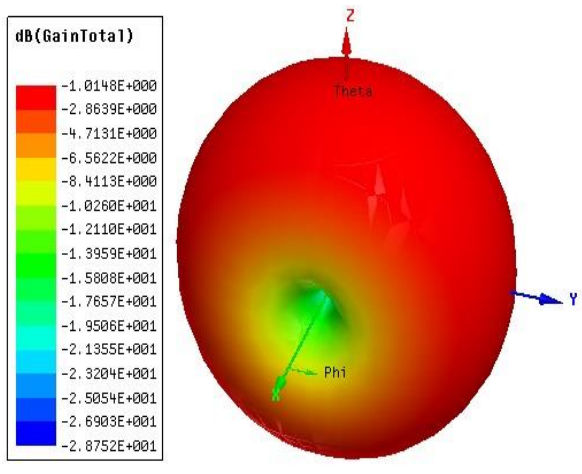

(a) $2 \mathrm{GHz}$

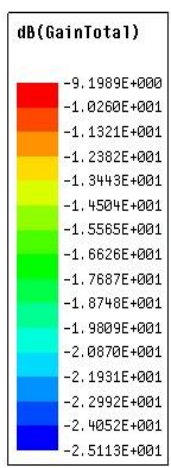

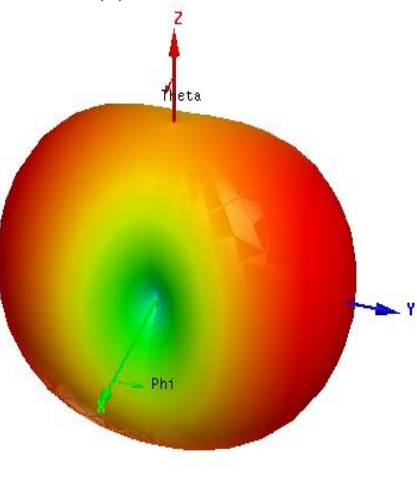

(d) $2.2 \mathrm{GHz}$
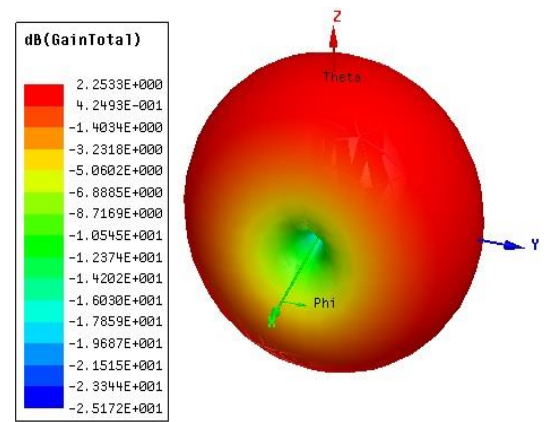

(b) $3.3 \mathrm{GHz}$

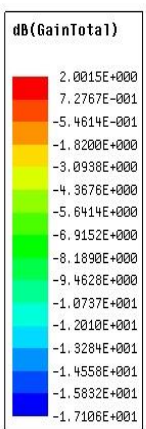

$-1.5832 E++6061$

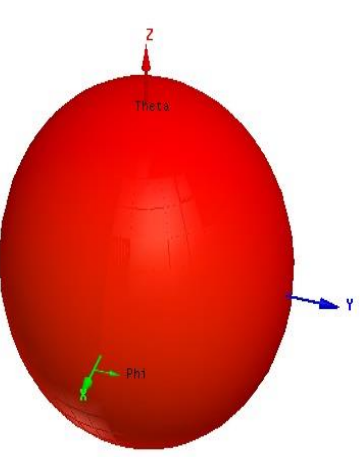

(e) $4.3 \mathrm{GHZ}$

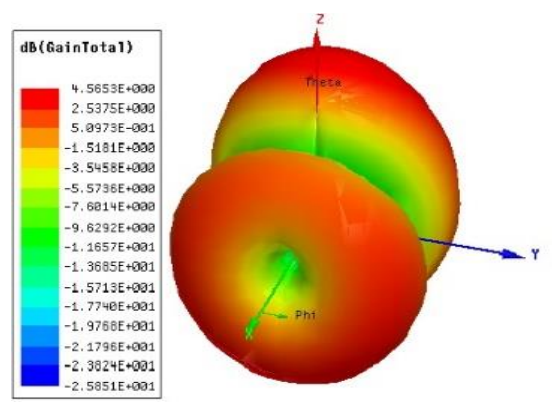

(c) $6 \mathrm{GHz}$

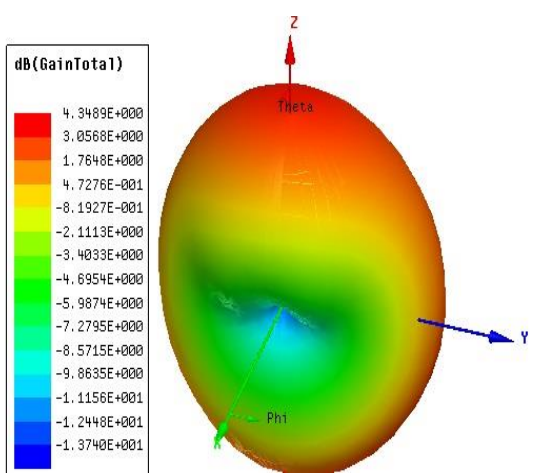

(f) $5.4 \mathrm{GHz}$

Fig. 6: Gain at working bands (a) $2 \mathrm{GHz}$ (b) $3.3 \mathrm{GHz}$ (c) $6 \mathrm{GHz}$, notch bands (d) $2.2 \mathrm{GHz}$ (e) $4.3 \mathrm{GHz}$ (f) $5.4 \mathrm{GHz}$ 


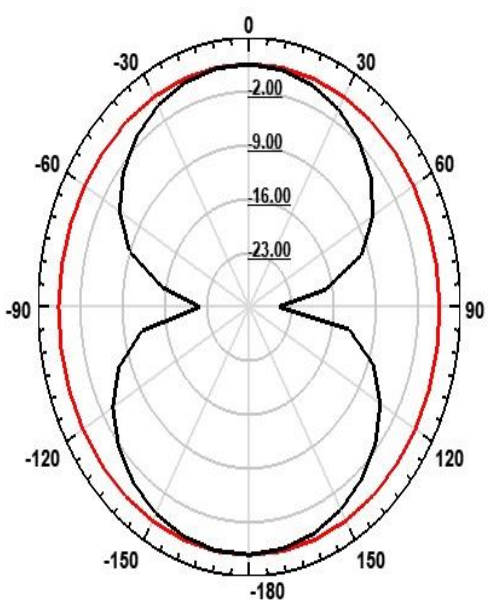

(a)

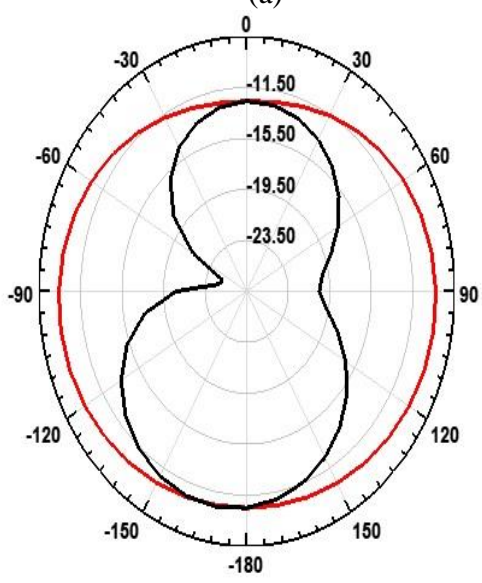

(d)

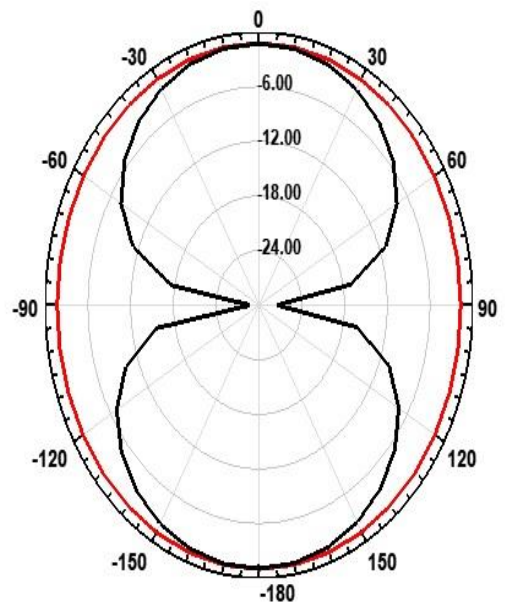

(b)

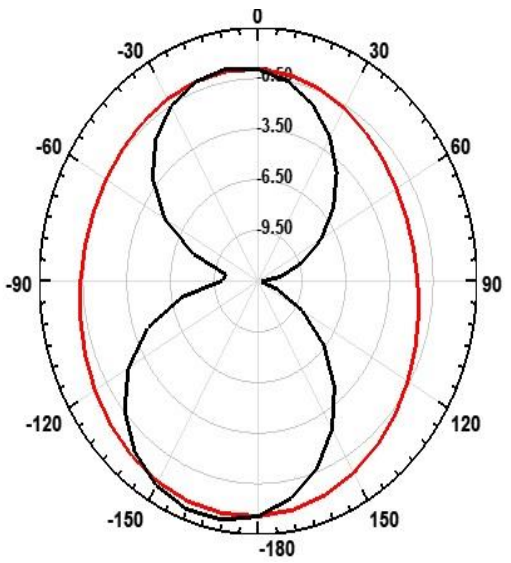

(e)

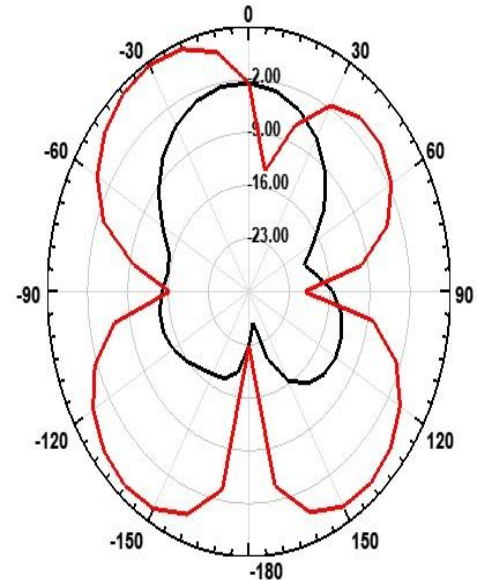

(c)

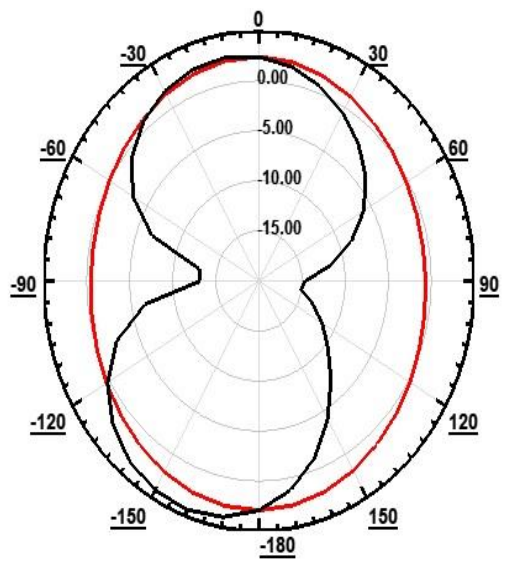

(f)

Fig. 7: Radiation patterns at working bands (a) $2 \mathrm{GHz}$ (b) $3.3 \mathrm{GHz}$ (c) $6 \mathrm{GHz}$, notch bands (d) $2.2 \mathrm{GHz}$, (e) $4.3 \mathrm{GHz}$, (f) $5.4 \mathrm{GHz}$

The fig 6 and 7 shows the gain and radiation patterns at both the working band and notch band. At working band, the gain is almost maintained stable at $3 \mathrm{~dB}$ whereas at notch band the gain depicts to $-9 \mathrm{db}$ and for another bands also the gain is negative. The radiation patterns indicate a omni directional patterns on the $\mathrm{H}$ plane and dipole type of patterns in the E-plane at the working bands. A variation is observed in the radiation patterns at the notch bands when compared to the working band. Table 1 shows the iteration wise application and band range and maximum return loss of the antenna. For proposed antenna a maximum gain of $4.5 \mathrm{db}$ with average gain of $2.5 \mathrm{db}$ is noticed

Table 2: comparing working bands of iteration models and its applications with proposed model
\begin{tabular}{|l|l|l|l|}
\hline Models & Max return loss & Bands & Applications \\
\hline Model 1 & $-28 \mathrm{db}$ & $2.44-2.80$ & WLAN \\
\hline Model 2 & $-25 \mathrm{db}$ & $2.60-3.3$, & Upper WLAN \\
& & $5.17-5.78$ & \\
\hline Proposed & $-30 \mathrm{db}$ & $1.95-2.04$, & LTE33-37, \\
model & & $2.87-3.76$, & Wi MAX, \\
& & $5.92-7.20$ & LTE 43-44 \\
\hline
\end{tabular}




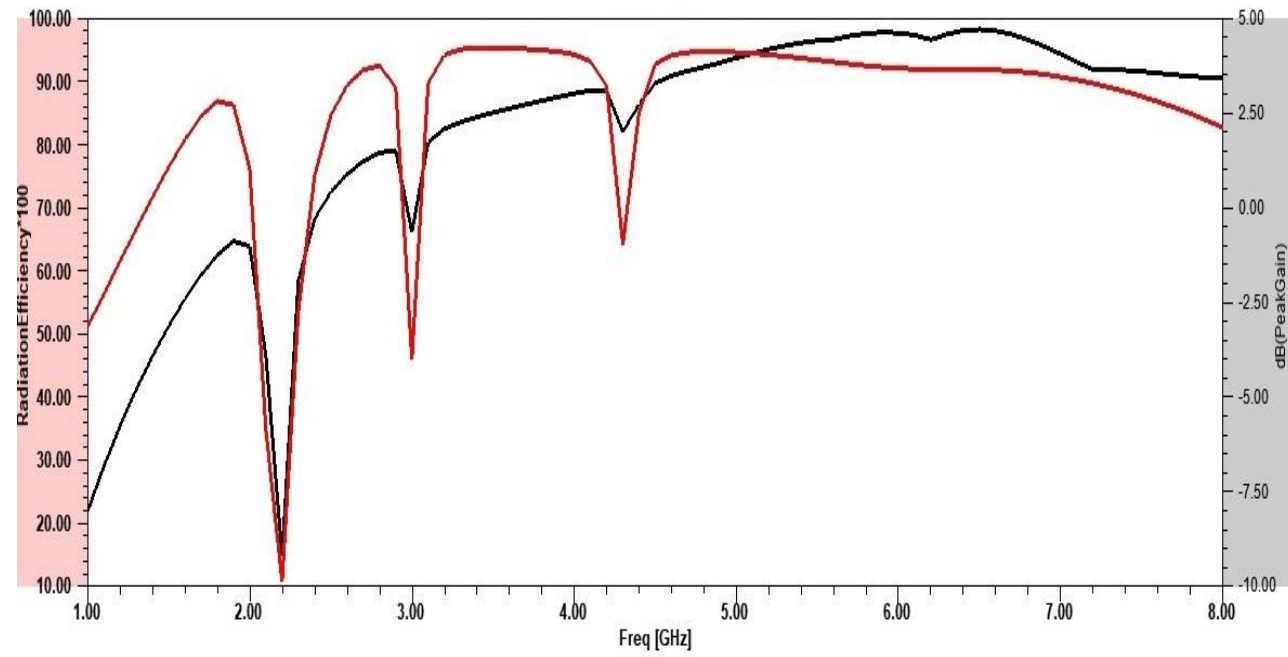

Fig. 8: Radiation efficiency/gain vs frequency of the proposed model

Fig 8 shows the radiation efficiency and gain with respect to frequency of the proposed antenna. Figure clearly indicates that at notch bands both radiation efficiency and the gain are less.at $2.2 \mathrm{GHz}$ the radiation efficiency is below 20percent and gain is $9 \mathrm{db}$. The notch band characteristics of the antenna shows good rejection at those bands. Average of $3.5 \mathrm{~dB}$ gain is maintained throughout the band at the proposed antenna and an average of $94 \%$ radiation efficiency is observed in the graph
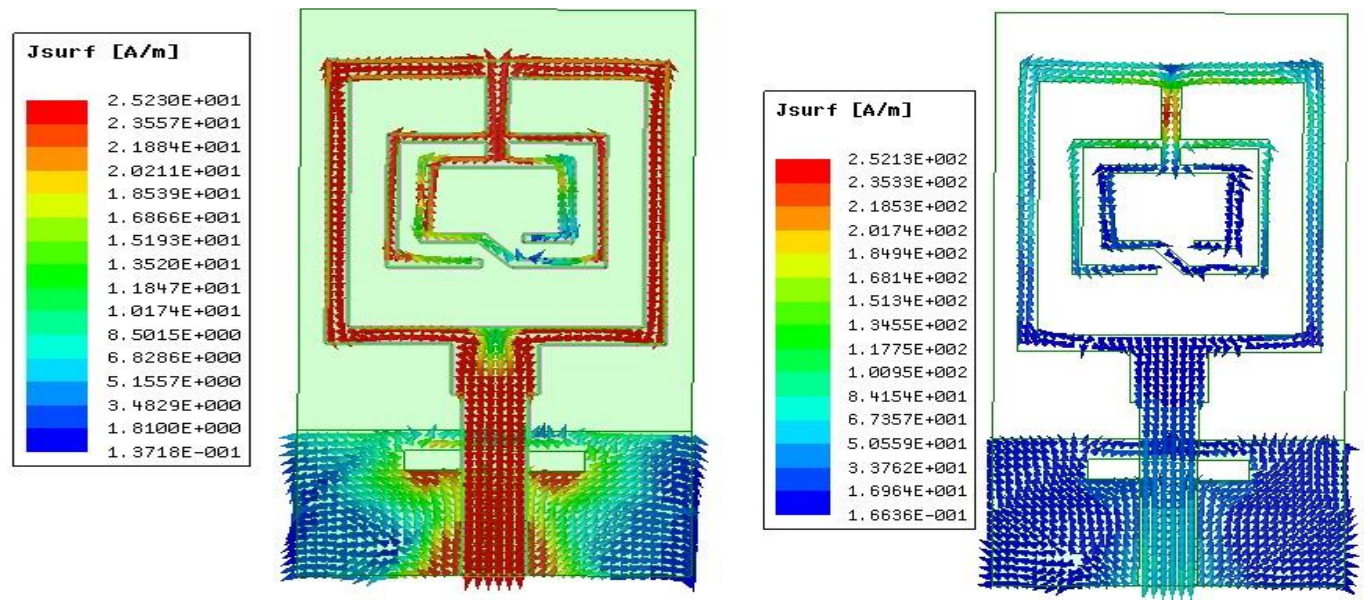

Fig. 9: Current distribution at working band $(2 \mathrm{GHz})$ and at notch band $(2.2 \mathrm{GHz})$ Parametric study
Fig 10 and Fig 11 shows parametric analysis of the proposed antenna. Fig 10 shows the width of the feedline. Figure shows the exact characteristics have been obtained at $4 \mathrm{~mm}$ only. Fig 11 shows the parametric analysis of the slit gap.at $1 \mathrm{~mm}$ the curve shows exact characteristics when compare to other values.i.e., $0.6 \mathrm{~mm}$ and $0.8 \mathrm{~mm}$

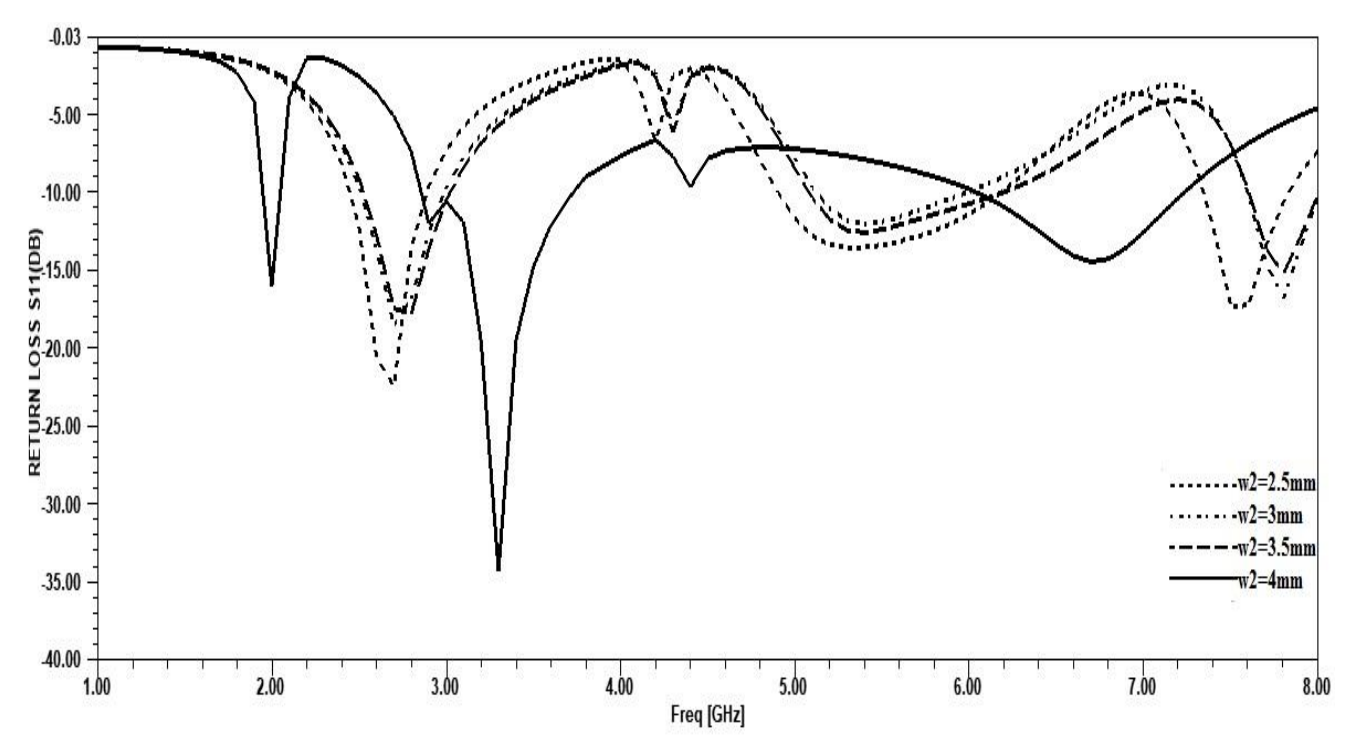

Fig. 10: width(w2) varying parametric analysis. 


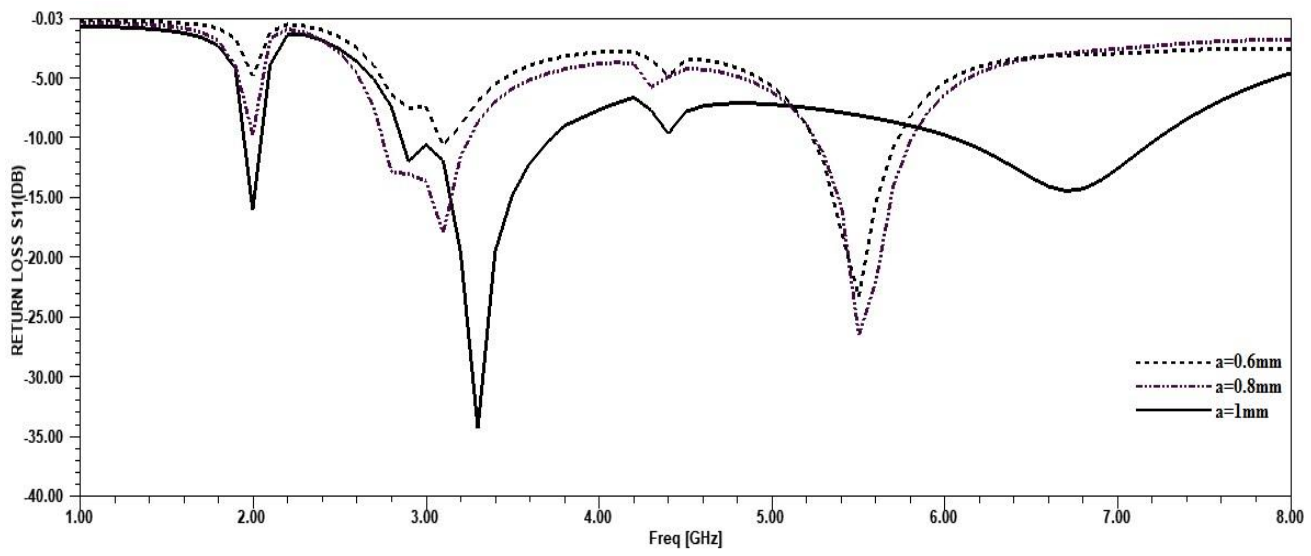

Fig. 11: Parametric analysis by varying Slit Gap of the proposed antenna

Table 3: comparison table of proposed work with other works

\begin{tabular}{|c|c|c|c|c|c|}
\hline References & dimensions & $\begin{array}{c}\text { Max Gain at notch } \\
\text { bands }\end{array}$ & No of Notches & Er & Metamaterial property \\
\hline$[12]$ & $46 \times 30$ & NA & 1 & 6.15 & No \\
\hline$[6]$ & $50 \times 50$ & -8 & 1 & 2.33 & No \\
\hline$[7]$ & $50 \times 50$ & NA & 1 & 2.2 & No \\
\hline$[8]$ & $47 \times 52$ & -8 & 3 & 3 & No \\
\hline$[9]$ & $38.5 \times 46.4$ & -8 & 2 & 2.65 & no \\
\hline $\begin{array}{c}\text { Proposed } \\
\text { model }\end{array}$ & $34 \times 18$ & -9 & 3 & 4.4 & yes \\
\hline
\end{tabular}

\section{Conclusion}

This paper shows simple compact antenna loaded with new metamaterials design approach. By placing the metamaterials unit cell, triple notch characteristics are obtained and depth in the resonant frequency has been observed. The parameters like gain, radiation pattern and return loss are analysed and parametric analysis is presented for optimization of the antenna. Average of $3.5 \mathrm{~dB}$ gain is maintained throughout the band and an average of $94 \%$ radiation efficiency is observed from the current model.

\section{Acknowledgements}

The authors deeply express their gratitude to ALRC Research Centre, Department of ECE, K L University for their encouragement during this work. Further, we express our gratitude to DST through ECR/2016/000569, FIST SR/FST/ETI-316/2012 and EEQ/2016/000604.

\section{References}

[1] Da Silva, José L., et al. "Microstrip patch antenna project with split ring resonator periodically arrayed on the substrate." Microwave and Optical Technology Letters 57.12 (2015): 2715-2720.

[2] Oh Kim, Dang, et al. "Multiband unidirectional planar monopole antenna with two split ring resonator pairs." Microwave and Optical Technology Letters 59.4 (2017): 753758.

[3] Rosaline, S. Immaculate, and S. Raghavan. "Design of split ring antennas for WLAN and WiMAX applications." Microwave and Optical Technology Letters 58.9 (2016): 2117-2122.

[4] Jackson, Beulah, and T. Jayanthy. "A novel microstrip slot antenna for permittivity measurement." Information Communication and Embedded Systems (ICICES), 2014 International Conference on. IEEE, 2014.

[5] Kumar, Arvind, and Praveen V. Naidu. "A compact O-shaped printed ACS fed monopole dual-band antenna for $2.4 \mathrm{GHz}$ Bluetooth and 5GHz WLAN/WiMAX applications." Progress in Electromagnetic Research Symposium (PIERS). IEEE, 2016.

[6] Siddiqui, Jawad Yaseen, Chinmoy Saha, and Yahia MM Antar "Compact SRR loaded UWB circular monopole antenna with frequency notch characteristics." IEEE Transactions on Antennas and Propagation 62.8 (2014): 4015-4020.

[7] Kandasamy, Krishnamurthy, et al. "Design of SRR loaded reconfigurable antenna for UWB and narrow band applications." Antennas and Propagation \& USNC/URSI National Radio Science Meeting, 2015 IEEE International Symposium on. IEEE, 2015.

[8] Zhang, Yan, et al. "A compact multiple bands notched UWB antenna by loading SIR and SRR on the feed line." Microwave and Millimetre Wave Technology, 2008. ICMMT 2008. International Conference on. Vol. 1. IEEE 2008.

[9] Li, Wen Tao, et al. "Planar antenna for 3G/Bluetooth/WiMAX and UWB applications with dual band-notched characteristics." IEEE Antennas and Wireless Propagation Letters 11 (2012): 61-64.

[10] Li, Wen Tao, et al. "Planar antenna for 3G/Bluetooth/WiMAX and UWB applications with dual band-notched characteristics." IEEE Antennas and Wireless Propagation Letters 11 (2012) 61-64.

[11] Yang, Yang, Xi Zhu, and Nemai C. Karmakar. "Microstrip low pass filter based on split ring and complementary split ring resonators." Microwave and Optical Technology Letters 54.7 (2012): 1723-1726.

[12] Qu, S-W., J-L. Li, and Quan Xue. "A band-notched ultra wideband printed monopole antenna." IEEE Antennas and Wireless Propagation Letters 5.1 (2006): 495-498.

[13] M Ajay babu, Flared V-Shape Slotted Monopole Multiband Antenna with Metamaterial Loading, International Journal of communications Antenna propagation, ISSN: 2039-5086, Vol 5, No 2, July-2015, pp 93-97.

[14] K V L Bhavani, Habibulla Khan, Multiband Slotted Aperture Antenna with Defected Ground Structure for C and X-Band Communication Applications, Journal of Theoretical and Applied Information Technology, ISSN: 1992-8645, Vol 82, No 3, Dec-2015, pp 454-461.

[15] B. T. P. Madhav, D. Naga Vaishnavi, G. Vanaja, G. Jayasree and S. Mounika, Design and analysis of met material antenna with EBG loading, Far East Journal of Electronics and Communications, ISSN: 0973-7006, Vol 14, No 2, 2015, pp 127-136.

[16] B.T.P. Madhav, D. Ujwala, Habibulla Khan, Multiband slot aperture stacked patch antenna for wireless communication applications, International Journal of Computer Aided Engineering and Technology, ISSN: 1757-2657, Vol. 8, No. 4 pp 413-423, Aug-2016

[17] K.Phanisrinivas, Multiband MSP Spiral Slot Antenna with Defected Ground Structure, ARPN Journal of Engineering and 
Applied Sciences, ISSN: 1819-6608, Vol. 11, No. 15, August 2016.

[18] T V Rama Krishna, Strip Loaded Closed Loop Resonator Based Multiband Defected Ground Structured Antenna, Journal of Engineering and Applied Sciences, ISSN: 1816-949X, Vol 11, No 6, 2016, pp 1417-1422.

[19] Dr. Seetaiah Kilaru, Hari Kishore K, Sravani T, Anvesh Chowdary L, Balaji T "Review and Analysis of Promising Technologies with Respect to fifth Generation Networks”, 2014 First International Conference on Networks \& Soft Computing, ISSN:978-1-4799-3486-7/14,pp.270-273, August 2014.

[20] D. S. Ramkiran, Pentagonal Shaped Koch Fractal Monopole Slot Antenna for Multiband Applications, ARPN Journal of Engineering and Applied Sciences, ISSN 1819-6608, Vol. 12, No. 15, February 2017.

[21] Habibulla Khan, A Cpw Fed U-Slot Multiband Fractal Antenna, International Journal of Pure and Applied Mathematics, ISSN: 1311-8080, Volume 115, No. 7, 2017, pp 459-463.

[22] B. L. Prakash, Metamaterial Inspired Tri-Band Antenna with SRR and Shorting Stub, ARPN Journal of Engineering and Applied Sciences, ISSN 1819-6608, VOL. 12, NO. 21, 2017, pp 6197-6205.

[23] Rajesh, M., and J. M. Gnanasekar. \&quot;GCCover Heterogeneous Wireless Ad hoc Networks.\&quot;Journal of Chemical and Pharmaceutical Sciences (2015): 195-200.

[24] S.V.Manikanthan and T.Padmapriya "Recent Trends In M2m Communications In 4g Networks And Evolution Towards 5g", International Journal of Pure and Applied Mathematics, ISSN NO:1314-3395, Vol-115, Issue -8, Sep 2017

[25] T. Padmapriya and V.Saminadan, "Handoff Decision for Multiuser Multiclass Traffic in MIMO-LTE-A Networks", 2nd International Conference on Intelligent Computing, Communication \& Convergence (ICCC-2016) - Elsevier Procedia of Computer Science, vol. 92, pp: 410-417, August 2016. 